Original Research Article

\title{
A prospective study of antimicrobial drug utilization in infective diseases in pediatrics at Navodaya Medical College Hospital of Raichur, Karnataka, India
}

\author{
Md Mohsin Ahmed ${ }^{1}$, Momin Mohd Abdul Mujeeb ${ }^{2 *}$
}

${ }^{1}$ Department of Pharmacology, KBN Institute of Medical Sciences, Gulbarga, Karnataka, India

${ }^{2}$ Department of Pharmacology, B.J. Government Medical College, Pune, Maharashtra, India

Received: 04 July 2018 Accepted: 10 July 2018

\section{*Correspondence to: \\ Dr. Momin Mohd Abdul Mujeeb, \\ Email: mominmujeeb23@ gmail.com}

Copyright: (C) the author(s), publisher and licensee Medip Academy. This is an openaccess article distributed under the terms of the Creative Commons Attribution NonCommercial License, which permits unrestricted noncommercial use, distribution, and reproduction in any medium, provided the original work is properly cited.

\begin{abstract}
Background: There is increased concern regarding the inappropriate use of antimicrobials resulting in emergence of resistant strains, unnecessary adverse effects and poor therapeutic outcome. This present study has been taken up with a view to analyze the use of various antimicrobial agents alone and/or in combination to combat diseases of infective origin in a proposed manner.

Methods: This was a prospective study carried out for a period of 1 year from January 2011 to December 2011. The prescriptions of all eligible patients were reviewed on daily basis and all the relevant data were retrieved to assess the utilization pattern of antimicrobials and also their safety and potential interactions.

Results: A total of 500 patients were selected randomly who satisfied the inclusion criteria. Of the total selected patients with infectious diseases, 493 patients $(98.6 \%)$ received one or more antimicrobials. Use of antimicrobials was high in the age group of ' 6 months to 3 years', 'rural patients' constituted $62 \%$ and were mostly from 'Lower Socio-economic status' (46\%). Respiratory diseases constituted $38 \%$ of the patients. Fever was the notable symptom in $68.4 \%$. Cephalosporins $(48.6 \%)$ were the most frequently prescribed class of antimicrobials. Combination of 'Parenteral therapy followed by oral therapy' was the preferred route in $92 \%$, and a combination of two antimicrobials was seen in $34.4 \%$. Majority of the patients $(81 \%)$ were discharged on advice and most of the patients $(37.6 \%)$ had duration of stay of 7-9 days. $25.8 \%$ reported 'Adverse Drug Reactions' including predictable and unpredictable reactions.

Conclusions: Antimicrobial prescribing is common in pediatric infectious diseases. As inappropriate usage of systemic antimicrobials was observed, it is essential that appropriate guidelines on the use of systemic antimicrobials are implanted to ensure rational prescribing of antimicrobials.
\end{abstract}

Keywords: Antimicrobials, Drug utilization evaluation, Prospective study, Rational drug use

\section{INTRODUCTION}

Patients' health mainly depends on the medications they receive. At the same time, the prescriber must remember that a scientific approach does not mean 'a patient must be treated as a mere biochemical machine'. It does not mean the exclusion of spiritual, psychological and social dimensions of human beings, but it does mean 'treating all these in a rational manner'.

Today's physician has an imposing arsenal of drugs. The remarkable spurt of potent drugs in the last two decades, has led to concern and perhaps over reaction that prescribing of drug may be unnecessary, inappropriate and even dangerous. Hence, the concept of drug utilization 
should be seriously considered. Drug utilization is defined as "the marketing, distribution, prescription and use of drugs in a society, with special emphasis on the resulting medical, social and economic consideration". ${ }^{2}$

The judicious use of antimicrobials in family practice in United States revealed $79 \%$ of prescriptions were unnecessary according to the Centre for Disease Control and Prevention (CDC) guidelines. ${ }^{3}$

Since the past few decades more attention is being given to rational prescribing. Drug utilization studies are playing a major role in this regard. These studies not only detect flaws in the therapy but also find out solutions to rectify the same.

World Health Organization (WHO) has already established, "Drug utilization Research Group (DURG)" in 1968 to monitor these studies and to prescribe the guidelines from time to time. ${ }^{4}$

Antimicrobials are the greatest contribution of the $20^{\text {th }}$ century to anti-infective therapies. ${ }^{5}$ As a class they are one of the most frequently used, as well as misused drugs. ${ }^{6}$ The inevitable consequence of the widespread use of antimicrobial agents has been the emergence of resistant pathogens, fuelling an ever increasing need for new drugs ${ }^{6}$. 'Monitoring of antimicrobial use' and 'knowledge of prescription habits' are some of the strategies recommended to contain resistance to antimicrobials in hospitalized patients. Antimicrobial resistance substantially raises, already-rising health care costs and increases patient morbidity and mortality. ${ }^{7}$

Drug Utilization Evaluation (DUE) is an ongoing, authorized, systematic quality improvement process designed to ensure that drugs are used appropriately, safely and effectively. ${ }^{8}$ The primary aim of DUE is to provide patient care through the optimization of therapy, which can be achieved through the ongoing review for use of drugs against standard criteria. The goals of this program include education of health care professionals with rational use of drugs, improve cost effectiveness in drug therapy by selecting the appropriate drug for appropriate period of time and avoiding the exposure of patients to unnecessary drugs. ${ }^{9}$ Monitoring reveals the trends in the prescribing pattern and allows comparisons to be made between hospitals. $^{10}$

Since infective diseases are the leading cause of morbidity and mortality among children in developing countries, causing majority of deaths in childhood, hence this present study has been taken up with a view to analyze the use of various antimicrobial agents alone and/or in combination to combat diseases of infective origin in a proposed manner.

The present study was undertaken to analyze the antimicrobial drug utilization in infectious diseases in pediatric age group for various infections at Navodaya Medical College, Raichur.

\section{Objectives}

- $\quad$ To assess the prescribing pattern of antimicrobials in pediatric infectious diseases in Navodaya Medical College Hospital and Research Center, Raichur.

- To determine the incidence of use of antimicrobials in pediatric infectious diseases.

- Hospital based studies to carry out a “THERAPEUTIC AUDIT" and to see,

- What is prescribed?

- What is the intention and rationale?

- To study the effectiveness of antimicrobials in the prevention and treatment of pediatric infections and time taken for control of infection.

- To assess the appropriateness of the antimicrobials usage.

- To assess the adverse reactions to various antimicrobials.

\section{METHODS}

\section{Study site}

The Navodaya Medical College Hospital and Research Center, Raichur is an 865 Bed urban tertiary care teaching hospital affiliated with The Rajiv Gandhi University of Health Sciences Karnataka, Bengaluru. The hospital has all major services as per the norms of the Medical Council of India (MCI). The institution covers a population of over 5 lakh inhabitants and has 40000-45000 patients/ admissions / year (an average of 120 admissions/day).

The study was carried out in the pediatric ward, Navodaya Medical College Hospital and Research Center, Raichur. The ward Consists of 110 Beds and has a turnover of 55006000 patients /year.

The total duration of the study was over a period of one year starting from $01^{\text {st }}$ January 2011 to $31^{\text {st }}$ December 2011. During this period the prescription data pertaining to 500 inpatients were collected from the day of admission of the patient to the day of discharge from the hospital. No follow up were done thereafter.

The study was approved by the Institute Human Ethical Committee, and permission for collection of data and to accompany physician in the pediatric ward was taken from Head of Pediatric Department, 'Navodaya Medical College Hospital and research center', before starting the study.

\section{Study design}

All the patients admitted to pediatric ward were reviewed daily to identify the patients with infective disorders and/or 
those prescribed with antimicrobials. Those patients who met the study criteria were enrolled into the study.

The prospective data collection of those who were subjected to infective diseases was done from the pediatric ward of all the units between 2 p.m. to 4 p.m. without disturbing the morning session, so as to facilitate the rounds by the professors, post graduates and interns of pediatric department. Discharge advice of those discharged during any other time was collected from the case sheet sent to Medical Record Department (MRD). In case of doubtful prescriptions, discussions was done with the concerned unit consultants.

\section{Source of data}

A written consent was taken from the parents/guardian explaining them about the reason for their interaction. Only upon their satisfactory will the particular data collection was initiated. The sources of data were physicians prescribing records, patient's medication profile and weekly, daily cards. Patient profile (age, sex, weight, height, patient's address), drugs prescribed (generic/brand name), doses and frequency were recorded. Interviews were conducted by using structured questionnaire (open question method).

\section{Inclusive criteria}

- Patients of either sex above 06 months of age.

- Evidence of infective disorder such as fever, diarrhea, cough etc.

- Patients prescribed with antimicrobials on inpatient basis.

\section{Exclusion criteria}

- $\quad$ Patients less than 06 months of age and more than 15 years of age.

- $\quad$ Patients with immune suppressive disorders.

- Patients on immune suppressive therapies.

- Patients with septal defects, thalassemias, metabolic disorders.

- $\quad$ Patients with chronic disorders such as tuberculosis, leprosy, syphilis, diabetes etc.

\section{Data analysis}

Descriptive statistics was used to analyze the results. The data was analyzed and the percentage value was calculated for the use of different class of antimicrobials. The nature and extent of use of each class and individual antimicrobial was also determined. The type of antimicrobial used for a particular disease condition was also determined.

The rationality of antimicrobials prescription was assessed with respect to various parameters such as indication, dose, frequency and duration of treatment. The prescriptions of all enrolled patients were checked for the appropriateness of use of antimicrobials. The rationality/appropriateness of antimicrobials with respect to various parameters such as indication, dose, frequency and duration was assessed by analyzing the collected data against standard texts, relevant literatures and available antimicrobial guidelines.

\section{RESULTS}

A total of 3697 patients were admitted in pediatrics department from January 2011 to December 2011, out of which 500 patients were selected randomly who satisfied the inclusion criteria. Out of the 500 selected patients 493 patients $(98.6 \%)$ received one or more antimicrobials.

Out of the 500 patients, $41.6 \%(n=208)$ of the patients were in the age group of 6 months to 3 years. $25 \%(n=125)$ of the patients were in the age group of 3-6 years. $11 \%(n=55)$ were in the age group of $6-9$ years. $15.4 \%(n=77)$ were in the age group of $9-12$ years and $7 \%(n=25)$ were in the age group of 12-15 years (Table 1).

Table 1: Age wise distribution of patients.

\begin{tabular}{|l|l|}
\hline Age of patients & No. of Patients $(\%)$ \\
\hline 6 months to 3 years & $208(41.6 \%)$ \\
\hline 3 years to 6 years & $125(25 \%)$ \\
\hline 6 years to 9 years & $55(11 \%)$ \\
\hline 9 years to 12 years & $77(15.4 \%)$ \\
\hline 12 years to 15 years & $25(7 \%)$ \\
\hline Total & $500(100 \%)$ \\
\hline
\end{tabular}

Out of the total (500) pediatric patients, $295(59 \%)$ were males and $205(41 \%)$ were females (Table 2$)$.

Table 2: Distribution of patients based on gender.

\begin{tabular}{|ll|}
\hline Sex of patients & No. of patients $(\%)$ \\
\hline Male & $295(59 \%)$ \\
\hline Female & $205(41 \%)$ \\
\hline Total & 500 \\
\hline
\end{tabular}

Out of the total 500 patients, $310(62 \%)$ of the Patients belongs to Rural and 190 (38\%) belongs to urban area (Table 3).

\section{Table 3: Rural/urban distribution of patients.}

\begin{tabular}{|ll|}
\hline Rural/urban & No. of patients $(\%)$ \\
\hline Rural & $310(62 \%)$ \\
\hline Urban & $190(38 \%)$ \\
\hline Total & $500(100 \%)$ \\
\hline
\end{tabular}

The 'lower class' 231 (46.2\%) constituted the majority of the patient in the study followed by 'lower middle' 224 (45.8\%), 'Upper middle' $26(5.2 \%)$, 'upper lower 13 $(2.6 \%)$ and 'Upper class' 6 (1.2\%) (Table 4).

Out of the 500 patients, most of them $92.8 \% \quad(n=464)$ presented with malnourished state according to 'Indian Academy of Pediatrics (IAP) Classification 1972'. 24.6\% 
$(n=123)$ were under nourished. $21.2 \% \quad(n=106)$ of the children were of Grade-1 malnutrition. $19.4 \%(n=97)$ were Grade-2 malnutrition. 14.8\% $(n=74)$ were of Grade-3 malnutrition. $13.4 \%(n=67)$ were of Grade-4 malnutrition (Table 5).

The relationship of various nutritional state and its association with various infectious diseases is also summarized; out of the 500 patients in the study 190 (38\%) were suffering from either of Respiratory infections, while $10(2 \%)$ were suffering from cardiovascular infection, 45 $(9 \%)$ were suffering from infections of the central nervous system, $33(6.6 \%)$ were diagnosed with typhoid, 125 (22\%) were diagnosed with Malaria, 103 (20.6\%) were suffering from gastrointestinal infections, $3(0.6 \%)$ were diagnosed with renal infections while $9(1.8 \%)$ patients were diagnosed with Protein Energy Malnutrition (PEM) with no significant infection (Table 5).

Table 4: Distribution of patients based on Socioeconomic status.

\begin{tabular}{|ll|}
\hline Socio-economic status & No. of patients \\
\hline Lower & $231(46.2 \%)$ \\
\hline Lower middle & $224(44.8 \%)$ \\
\hline Upper lower & $13(2.6 \%)$ \\
\hline Upper middle & $26(5.2 \%)$ \\
\hline Upper & $6(1.2 \%)$ \\
\hline Total & $500(100 \%)$ \\
\hline
\end{tabular}

Table 5: The relation of 'Nutrition status' to infectious diseases.

\begin{tabular}{|llllllll|}
\hline $\begin{array}{l}\text { Infectious } \\
\text { diseases }\end{array}$ & $\begin{array}{l}\text { Normal } \\
(\mathbf{n = 3 6})\end{array}$ & $\begin{array}{l}\text { Grade 1 } \\
(\mathbf{n = 1 0 6})\end{array}$ & $\begin{array}{l}\text { Grade 2 } \\
(\mathbf{n = 9 7 )}\end{array}$ & $\begin{array}{l}\text { Grade 3 } \\
(\mathbf{n = 7 4 )}\end{array}$ & $\begin{array}{l}\text { Grade 4 } \\
(\mathbf{n = 6 7 )}\end{array}$ & $\begin{array}{l}\text { Under nourished } \\
(\mathbf{n = 1 2 3})\end{array}$ & Total \\
\hline Respiratory & - & 62 & 57 & 16 & 17 & 38 & $190(38 \%)$ \\
\hline CVS & 6 & 3 & - & - & - & 1 & $10(2 \%)$ \\
\hline CNS & 13 & 15 & 7 & 3 & 2 & 5 & $45(9 \%)$ \\
\hline Typhoid & - & 3 & 7 & 6 & 1 & 16 & $33(6.6 \%)$ \\
\hline Malaria & 17 & 23 & 15 & 19 & - & 36 & $110(22 \%)$ \\
\hline Gastro intestinal & - & - & 10 & 26 & 44 & 23 & $103(20.6 \%)$ \\
\hline Renal & - & - & 1 & - & - & 2 & $3(0.6 \%)$ \\
\hline PEM only & - & - & - & 4 & - & 2 & $6(1.2 \%)$ \\
\hline
\end{tabular}

Out of the 500 patients in the study, various patients were suffering from multiple symptoms, fever was the most dominating symptom affecting $342(68.4 \%)$ patients, Cough affecting 195 (39\%) patients, vomiting affecting $115(23 \%)$ patients, loose stools affecting $95(19 \%)$ patients, convulsions affecting 35 (7\%) patients, painabdomen/head ache affecting $30(6 \%)$ patients and yellowish discoloration affecting 15 (3\%) patients (Table $6)$.

Table 6: Incidence of presenting symptoms.

\begin{tabular}{|ll|}
\hline Symptoms & No of patients \\
\hline Fever & $342(68.4 \%)$ \\
\hline Cough & $195(39 \%)$ \\
\hline Loose stools & $95(19 \%)$ \\
\hline Vomiting & $115(23 \%)$ \\
\hline Convulsions & $35(7 \%)$ \\
\hline Pain - abdominal/headache & $30(6 \%)$ \\
\hline Yellowish discoloration & $15(3 \%)$ \\
\hline
\end{tabular}

Out of the 500 patients in the present study with infections $158(31.6 \%)$ had a past history of similar infections, while $342(68.4 \%)$ had no past history of similar infections (Table 7).
Table 7: Incidence of preceding infections.

\begin{tabular}{|ll|}
\hline Category & No of patients (\%) \\
\hline $\begin{array}{l}\text { Patients with Past history of } \\
\text { similar infections }\end{array}$ & $158(31.6 \%)$ \\
\hline $\begin{array}{l}\text { Patients with no Past history of } \\
\text { similar infections }\end{array}$ & $342(68.4 \%)$ \\
\hline Total & $500(100 \%)$ \\
\hline
\end{tabular}

In the present study, cephalosporins $(n=243)$ were the most frequently prescribed class of anitmicrobials followed by Penicillines $\quad(n=235), \quad$ aminoglycosides $\quad(n=229)$ antimalarial $(\mathrm{n}=199)$ anthelmintic $(\mathrm{n}=114)$ and many more (Table 8).

Out of the 500 patients in the present study, most of the patients $460(92 \%)$ received a combination of 'parenteral and oral therapy', followed by $26(5.2 \%)$ patients receiving only oral therapy and $14(2.8 \%)$ patients receiving only parenteral therapy (Table 9).

Out of the 500 patients in the study, $122(24.4 \%)$ patients received single antimicrobial therapy, while $172(34.4 \%)$ patients received a combination of two antimicrobials, 153 $(30.6 \%)$ patients received a combination of three 
antimicrobials and $53(10.6 \%)$ patients received a combination of more than three antimicrobials (Table 10).

Table 8: Prescribing pattern of antimicrobials.

\begin{tabular}{|lll|}
\hline Prescribing pattern & IV & Oral \\
\hline Ceftriaxone (T1) & 33 & - \\
\hline Amoxicillin (T2) & 56 & 52 \\
\hline Gentamicin (T3) & 105 & - \\
\hline Azithromycine (T4) & - & 15 \\
\hline Ampicilline (T5) & 178 & - \\
\hline Ampicilline + Cloxacillin (T6) & 60 & 25 \\
\hline Amoxcilline + Clavulanic acid (T7) & 115 & 72 \\
\hline Amikacin (T8) & 102 & - \\
\hline Cefotaxime (T9) & 30 & - \\
\hline Cefpodoxime proxetil (T10) & 26 & - \\
\hline Cefixime (T11) & 128 & - \\
\hline Ciprofloxacin (T12) & 10 & 12 \\
\hline Cefoperazone + Sulbactam (T13) & 12 & - \\
\hline Co-trimoxazole (T14) & - & 20 \\
\hline Ceftriaxone + Tazobactam (T15) & 26 & - \\
\hline Crystalline Penicillin (T16) & 11 & - \\
\hline Quinine (T17) & 91 & 69 \\
\hline Chloroquine (T18) & - & 30 \\
\hline Arteether (T19) & 9 & - \\
\hline Diethyl carbamazine (T20) & 14 & - \\
\hline Metronidazole (T21) & 13 & 61 \\
\hline Netilmicine (T22) & 22 & - \\
\hline Albendazole (T23) & - & 67 \\
\hline Albendazole + Ivermectine (T24) & - & 33 \\
\hline & & \\
\hline
\end{tabular}

Table 9: Distribution of patients based on 'Routes of drug administration'.

\begin{tabular}{|ll|}
\hline Route & No. of patients \\
\hline Oral only & $26(5.2 \%)$ \\
\hline Parenteral only & $14(2.8 \%)$ \\
\hline Parenteral + Oral & $460(92 \%)$ \\
\hline Total & $500(100 \%)$ \\
\hline
\end{tabular}

Table 10: Number of antimicrobials used.

\begin{tabular}{|ll|}
\hline Antimicrobials & No. of patients (\%) \\
\hline Single & $122(24.4 \%)$ \\
\hline Double & $172(34.4 \%)$ \\
\hline Triple & $153(30.6 \%)$ \\
\hline More than Three & $53(10.6 \%)$ \\
\hline Total & $500(100 \%)$ \\
\hline
\end{tabular}

Out of 500 patients most of the patients $405(81 \%)$ were discharged on advise after complete cure, while 68 $(13.6 \%)$ were either discharged against medical advice or were found absconded without any information, 27 (5.4\%) were referred to higher center (Table 11).

In the Present study, out of the 500 patients $30(6 \%)$ patients stayed for 1-3 days, 180 (36\%) patients stayed for
4-6 days, 188 patients (36\%) stayed for 1-9 days and 102 $(20.4 \%)$ stayed for more than nine days. Hence most of the inpatients in this study stayed for a duration of 7-9 days (Table 12).

\section{Table 11: Distribution of patients based on} 'Discharge position'.

\begin{tabular}{|ll|}
\hline Discharge position of patient & No. of Patients \\
\hline On advise & $405(81 \%)$ \\
\hline Against advise & $68(13.6 \%)$ \\
\hline Referred to higher center & $27(5.4 \%)$ \\
\hline Total & $500(100 \%)$ \\
\hline
\end{tabular}

Table 12: Distribution of patients based on 'Duration of stay'.

\begin{tabular}{|ll|}
\hline No. of days & No. of patients \\
\hline $1-3$ & $30(6 \%)$ \\
\hline $4-6$ & $180(36 \%)$ \\
\hline $7-9$ & $188(37.6 \%)$ \\
\hline$>9$ & $102(20.4 \%)$ \\
\hline Total & $500(100 \%)$ \\
\hline
\end{tabular}

The adverse events experienced by the study patients are presented in Table 6.

Out of the 500 patients in the study, a total of 129 (25.8\%) adverse drug reactions were reported during the study period. Of the total ADRs reported $68.2 \%(n=88)$ were mild and $29.5 \%(n=38)$ of the reactions were moderate in their severity while $2.3 \% \quad(n=3)$ were severe. All the adverse drug reactions that occurred were predictable.

Table 13: Adverse effects of antimicrobials.

\begin{tabular}{|c|c|c|}
\hline Type & Adverse effect & No. of patients \\
\hline \multirow{7}{*}{$\begin{array}{l}\text { Mild } \\
(\mathrm{n}=88)\end{array}$} & Diarrhea & 18 \\
\hline & Vomiting & 29 \\
\hline & $\begin{array}{l}\text { Allergic skin reaction/ } \\
\text { Rashes }\end{array}$ & 24 \\
\hline & Erythematous papules & 8 \\
\hline & Dizziness & 2 \\
\hline & Headache & 2 \\
\hline & Abdominal pain & 5 \\
\hline \multirow{8}{*}{$\begin{array}{l}\text { Moderate } \\
(n=38)\end{array}$} & Thrombophlebitis & 3 \\
\hline & Hepatitis & 5 \\
\hline & Vomiting & 8 \\
\hline & Erthematous papules & 7 \\
\hline & Jaundice & 4 \\
\hline & Diarrhea & 8 \\
\hline & Anaphylactic reactions & 2 \\
\hline & Thrombocytopenia & 1 \\
\hline \multirow{2}{*}{$\begin{array}{l}\text { Severe } \\
(\mathrm{n}=3)\end{array}$} & $\begin{array}{l}\text { Steven Johnson's } \\
\text { syndrome }\end{array}$ & 1 \\
\hline & Anaphylactic reactions & 2 \\
\hline
\end{tabular}


The causality assessment of ADRs reported found that $44.68 \%(n=63 \%)$ were possible, $38.30 \% \quad(n=54)$ were probable and $18.44 \%(n=26)$ were conditional using three probability scales (WHO's probability scale and Naranjo scale) (Table 13).

Out of the 500 patients in the study, 367 (73.4\%) patients received appropriate treatment based on indication of antimicrobial therapeutic use, 409 (81.8\%) received appropriate treatment based on dosage of antimicrobial therapeutic use, $442(88.4 \%)$ received appropriate treatment based on frequency of antimicrobial administration and $309(61.8 \%)$ received appropriate treatment based on duration of antimicrobial administration (Table 14).

\section{Table 14: Overall appropriateness of use of antimicrobials.}

\begin{tabular}{|ll|}
\hline Category & $\begin{array}{l}\text { No. of patients being given } \\
\text { appropriate treatment }(\%)\end{array}$ \\
\hline Based on duration & $367(73.4 \%)$ \\
\hline $\begin{array}{l}\text { Based on frequency } \\
\text { of administration }\end{array}$ & $409(81.8 \%)$ \\
\hline $\begin{array}{l}\text { Based on dosage of } \\
\text { administration }\end{array}$ & $442(88.4 \%)$ \\
\hline Based on indication & $309(61.8 \%)$ \\
\hline
\end{tabular}

Of the $500(100 \%)$ patients reviewed, a total of $85(17 \%)$ interactions were identified. Of those 85 (100\%) interactions identified, most of the interactions belonged to significance level 5 [44.71\% $(n=38)]$ followed by level 1 [25.88\% $(n=22)]$ and level 2 [17.65\% $(n=15)]$ (Table 15).

\section{Table 15: The level of significance of antimicrobial interaction.}

\begin{tabular}{|ll|}
\hline Category & No. of patients (\%) \\
\hline Significance Level 1 & $22(25.88 \%)$ \\
\hline Significance Level 2 & $15(17.65 \%)$ \\
\hline Significance Level 3 & $6(7.06 \%)$ \\
\hline Significance Level 4 & $4(4.71 \%)$ \\
\hline Significance Level 5 & $38(44.71 \%)$ \\
\hline Total & $85(100 \%)$ \\
\hline
\end{tabular}

\section{DISCUSSION}

Drug utilization evaluation (DUE) is an inexpensive, flexible and simple method to assess the utilization pattern of drugs. DUE has defined potential benefits both for patient and clinical practitioners in carrying out a well planned audit of prescribing drugs. Infectious diseases in children less than 15 years of age constitute a common clinical problem encountered in day to day practice.

Therefore, rational use of antimicrobials demands that an appropriate antimicrobial should be prescribed. This study was focused on the evaluation pattern of the antimicrobial use in pediatrics at Navodaya Medical College Hospital and Research Center.

Of the 500 patients reviewed, the incidence of use of antimicrobials was found to be $99.6 \%$. The reason antimicrobials were prescribed to such a large extent is due to the large number of patients who presented to the hospital with infectious diseases. In the present study, majority of the patients presented with conditions like respiratory tract infections (RTI), malaria, typhoid, gastroenteritis (GE), measles etc.

The present study showed variations in the distribution of patients in different age groups. Most of the patients in the present study $(41.6 \%)$ were in the age group of ' 6 months to 3 years', while least $(7 \%)$ patients were in the aged group of 12-15 years. The major reason for the higher number of patients in the age group of ' 6 months to 3 years' was the higher incidence of co-morbidities seen in this group of patients. Younger children are more liable to develop infectious diseases as compared to the elder. Hence the younger age group constituted the majority of patients in this age group.

Of the 500 patients treated with antimicrobials, 59\% $(n=295)$ were males and $41 \%(n=205)$ were females. Majority of the patients admitted with infectious diseases belonged to rural area $62 \%(n=310)$ while patients from urban area constituted only $38 \%(\mathrm{n}=190)$. This high number of cases admitted from rural areas was due to the fact that the prevalence of infectious diseases is high in the rural areas due to lack of sanitation and lack of awareness of people towards health.

The socio-economic status of the patients was classified according to modified Kuppuswamy scale into 5 groups. ${ }^{11}$ In this study, greater majority of the patients belonged to 'lower' $(46.2 \%)$ as well as 'lower middle class' (44.8\%).

Out of the 500 patients in the study 190 (38\%) were infected with either of 'Respiratory infections', while 10 $(2 \%)$ were infected with 'cardiovascular infection', 45 $(9 \%)$ were suffering from infections of the 'central nervous system', 33 (6.6\%) were diagnosed with 'typhoid', 125 (22\%) were diagnosed with 'Malaria', 103 (20.6\%) were suffering from 'gastrointestinal infections', $3(0.6 \%)$ were diagnosed with 'renal infections' while $9(1.8 \%)$ patients were diagnosed with 'Protein Energy Malnutrition'(PEM) with no significant infection. As far as the nutritional status in the patients with infectious disease in this study is concerned, $92.8 \% \quad(n=464)$ of the patients were malnourished according to 'Indian Academy of Pediatrics (IAP) Classification 1972'. 24.6\% $(n=123)$ were under nourished. $21.2 \%(n=106)$ of the children were of Grade-1 malnutrition. 19.4\% ( $\mathrm{n}=97)$ were Grade-2 malnutrition. $14.8 \%(n=74)$ were of Grade-3 malnutrition. $13.4 \%(n=67)$ were of Grade-4 malnutrition.

Out of the 500 patients in the study, Various patients were suffering from multiple symptoms, Fever was the most 
dominating symptom affecting 342 patients, followed by cough 195 patients, vomiting affecting 115 patients, loose stools affecting 95 patients, convulsions affecting 35 patients, pain (abdominal/head ache) affecting 30 patients and yellowish discoloration affecting 15 patients.

Out of the 500 patients in the present study with infectious diseases, $158(31.6 \%)$ had a 'past history of similar infections', while $342(68.4 \%)$ has 'no past history of similar infections'.

Amongst the blood indices 'Raised ESR' was notable in most of the cases of infectious diseases while alternation in other blood indices such as 'Total WBC count', 'Neutrophile count' 'Lymphocyte count' were minimal. 'Monocytes' and 'Basophils' were not raised in any of the case of infectious diseases recruited in this study.

In the present study, Cephalosporins $(n=243)$ were the most frequently prescribed class of antimicrobials followed by Penicillines $(n=235)$, Aminoglycosides $(n=229)$, Antimalarials $(n=199)$, Anthelmintics $(n=114)$ and many more.

Out of the 500 patients in the present study, most of the patients $460(92 \%)$ received a combination of oral and parenteral therapy (parenteral antimicrobial therapy followed by oral therapy), $26(5.2 \%)$ patients received only oral antimicrobial therapy and $14(2.8 \%)$ patients received only parenteral antimicrobial therapy. This is irrespective of the other medicines (non antimicrobials) used concurrently as adjuvant or for symptomatic relief. Those patients who had severe infections were prescribed with 'parenteral therapy'. The patients were administered with 'parenteral therapy' for their severe conditions, as the patients condition improved, the 'parenteral route' was changed to 'oral'. Patients with less severe infections were started with 'oral therapy'. 'Oral therapy' was used because it was 'easy to administer', would cause 'minimum discomfort' to the patient, it would 'cost less' and ensure 'better compliance' to the treatment. Parenteral therapy was used alone when a particular antimicrobial prescribed against a particular disease was available only in the parenteral form or the age of the pediatric patient was such that exact calculation of the dose in oral form was unreliable. The selection of proper route of antimicrobial depends on severity of infection and bioavailability. The use of parenteral route was preferred for faster onset of action and for the management of severely disabled and non co-operative pediatric patients.

In the Present study, out of the 500 patients $30(6 \%)$ patients stayed for 1-3 days, $180(36 \%)$ patients stayed for 4-6 days, 188 patients (37.6\%) stayed for 1-9 days and 102 $(20.4 \%)$ stayed for more than nine days. Hence most of the inpatients in this study stayed for 7-9 days.

Out of the 500 patients in the study, 122 (24.4\%) patients received single antimicrobial therapy, while 172 (34.4\%) patients received a combination of two antimicrobials, 153
(30.6\%) patients received a combination of three antimicrobial and $53(10.6 \%)$ patients received a combination of more than three antimicrobials.

Out of 500 patients most of the patients 405 (81\%) were discharged on advice after complete cure, while 68 (13.6\%) were either discharged against medical advice or were found absconded without any information, 27 (5.4\%) were referred to higher center.

Out of the 500 patients in the study, a total of 129 (25.8\%) adverse drug reactions were reported during the study period.

Of these reported ADR's 68.2\% ( $\mathrm{n}=88)$ were mild and $29.5 \%(n=38)$ of the reactions were moderate in their severity, while $2.3 \%(n=3)$ were severe. All the adverse drug reactions that occurred were predictable.

The causality assessment of ADR's was done using standard Naranjo ADR probability scale. ${ }^{12}$ As per the scales we found that $44.68 \%(n=63 \%)$ were possible, $38.30 \%(n=54)$ were probable and $18.44 \%(n=26)$ were conditiona/doubtful ADR.

\section{CONCLUSION}

Antimicrobials prescribing among pediatric age group is common in this hospital set up. However, the use of antimicrobials as a definite therapy was low. Our study revealed, although not to a greater extent, inappropriate use of antimicrobials. There is a great need for the adoption of various strategies to prevent/minimize the inappropriate use of systemic antimicrobials in order to improve the quality use of medicines. As many number of significant interactions and ADR's were found, designing and implementation of mechanisms which constantly monitor the potential interactions and adverse drug events is needed.

There is a need for implementation of appropriate antimicrobial guidelines to promote the rational use of antimicrobials.

Various strategies need to be developed and implemented to minimize the drug interactions and adverse drug reactions associated with the use of antimicrobials in pediatrics.

\section{ACKNOWLEDGEMENTS}

The author would like to thank Dr. S Ramabhimaiah, Prof. and Head Department of Pharmacology, NMC Raichur, Dr. VN Biradar, M.D., Professor of Pharmacology and Dr. GA Manjunath, M.D., Professor and Head, Department of Pediatrics, for their dynamic able guidance, valuable advice, constant support and encouragement.

Funding: No funding sources

Conflict of interest: None declared 
Ethical approval: The study was approved by the Institutional Ethics Committee of Navodaya Medical College, Raichur, India

\section{REFERENCES}

1. Powell JR, Cali TJ, Linkwich JA. Inadequately written prescription: As directed' Prescription Analysed. Journal of American Medical Association. JAMA. 1973; 226(8):999-1000.

2. Uppal R. Vijaya Rajendran. Drug Utilization Studies, PGI. Bulletin. 1996;20:1-5.

3. Mohan S, Dharamraj K, Dindial R, Mathur D, Parmasad V, Ramdhanie J, et al. Physician behaviour for antimicrobial prescribing for paediatric upper respiratory tract infections: a survey in general practice in Trinidad, West Indies. Annals of Clinical Microbiology and Antimicrobials. 2004 Dec;3(1):11.

4. Traub R, Wisseman CL. Bulletin of the World Health Organization, Ecological Considerations in Scrub Typhus 2. Vector Species. 1968;39(2):219-30.

5. Triparthi KD. Antimicrobial Drugs General Consideration. In: K.D Triparthi's, Essentials of Medical Pharmacology, Jaypee Brothers Medical Publications, $7^{\text {th }}$ Ed.; 2013:688-689.

6. Gumbo T. Chemotherapy of Infectious Diseases. In: Laurence L. Brunton, Bruce A. Chabner, Bjorn C. Knollmann, Goodman and Gilman's, The Pharmacological Basis of Therapeutics; 13 ${ }^{\text {th }}$ Ed; McGraw Hill; 2010:955-968.
7. Krivoy N, El-Ahal WA, Bar-Lavie Y, Haddad S. Antibiotic prescription and cost patterns in a general intensive care unit. Pharmacy Practice. 2007;5(2):6773.

8. Sathwik BS. Drug utilization Evaluation. In G. Parthasarathi, Karin Nyfort-Hansen, Milap C Nahata. A textbook of clinical pharmacy practice: Essential concepts and skills. $2^{\text {nd }}$ Ed. Orient Blackswan Private Limited; 2012;362-375.

9. Misan GMH. The members of society of hospital pharmacists of Australia. SHPA standards of practice for drug usage evaluation in Australian hospitals. Australia. 1998;2:15.1-15.7.

10. Müller-Pebody B, Muscat M, Pelle B, Klein BM, Brandt CT, Monnet DL. Increase and change in pattern of hospital antimicrobial use, Denmark, 19972001. J Antimicr Chemother. 2004 Dec 1;54(6):11226.

11. Saleem SM. Modified Kuppuswamy scale updated for Year 2018, Paripex. Ind J Resear. March-2018;7(3):1.

12. Zaki SA. Adverse drug reaction and causality assessment scales. Lung India. Official Organ of Indian Chest Society. 2011;28(2):152-3.

Cite this article as: Ahmed MM, Mujeeb MMA. A prospective study of antimicrobial drug utilization in infective diseases in pediatrics at Navodaya Medical College Hospital of Raichur, Karnataka, India. Int J Basic Clin Pharmacol 2018;7:1498-505. 